\title{
Reminder-induced attenuation of the effect of relative stimulus validity
}

\author{
ROBERT P. COLE, JAMES C. DENNISTON, and RALPH R. MILLER \\ Binghamton University, Binghamton, New York
}

\begin{abstract}
The roles of deficient acquisition and deficient expression of learned information in the effect of relative stimulus validity were examined using rats in a conditioned lick suppression paradigm. Recovery from the effect without further pairings of the conditioned stimulus (CS) and the unconditioned stimulus (US) would favor an interpretation of the relative validity effect based on a latent CS-US association as distinct from a failure to acquire the CS-US association. As a potential recovery manipulation, "reminder" treatments, consisting of the US alone (Experiment 1) or the CS alone (Experiment 2), were administered following relative validity training. In both cases, subjects for which the CS target was of low relative predictive validity exhibited enhanced responding relative to appropriate controls. Additionally, Experiment 2 showed that the amelioration of the relative validity deficit was stimulus specific. Thus, the results of these experiments support previous suggestions that the performance deficit resulting from low relative stimulus validity is due, at least in part, to a failure to express acquired information (Cole, Barnet, \& Miller, 1995a). This conclusion is discussed as a part of the larger issue of acquisition versus performance failures.
\end{abstract}

Cue competition effects arise in situations in which two or more conditioned stimuli (CSs) are presented together in a predictive relationship with an unconditioned stimulus (US). Empirically, cue competition effects are evidenced through an attenuation in responding to one of those CSs (henceforth referred to as the target CS) relative to that seen if the target CS alone had been paired with the US. Cue competition in Pavlovian conditioning includes blocking (see, e.g., Kamin, 1969), overshadowing (e.g., Kamin, 1969; Mackintosh, 1976; Pavlov, 1927), and the effect of relative stimulus validity (e.g., Wagner, Logan, Haberlandt, \& Price, 1968; Wasserman, 1974). Traditionally, most major theories of conditioning have explained cue competition as an acquisition deficit, defined here as a failure to initially encode a training event (see, e.g., Hawkins \& Kandel, 1984; Mackintosh, 1975; Pearce, 1987; Pearce \& Hall, 1980; Rescorla \& Wagner, 1972; Thompson, 1986). However, some models have suggested explanations of cue competition effects that emphasize differences in the expression of acquired information rather than differences in information acquisition. For example, Gibbon and Balsam (1981); Miller, Kasprow, and Schachtman (1986); and Miller and Matzel (1988) have suggested that the performance deficits witnessed in cue competition effects are due to a failure to retrieve or express information previously acquired. To better illustrate how these two families of theories address cue

Support for this research was provided by National Institute of Mental Health Grant 33881. We thank Nicholas Grahame, Lisa Gunther, and Philippe Oberling for comments on earlier versions of this manuscript and Lee Mattes for assistance with data collection. Correspondence should be addressed to R. R. Miller, Department of Psychology, Binghamton University, Binghamton, NY 13902-6000 (e-mail: rmiller@bingvmb.cc.binghamton.edu). competition, we focus on a specific example, the effect of relative stimulus validity.

The relative validity effect was initially demonstrated by Wagner et al. (1968). They trained two groups of rats using a discrete trial procedure in which subjects were reinforced on $50 \%$ of the total trials for barpressing in the presence of a light $(\mathrm{X})$ that was presented in compound equally often with one of two auditory stimuli (A and B). One group (uncorrelated) was reinforced for leverpressing with equal probability during $\mathrm{AX}$ and $\mathrm{BX}$ trials. That is, responding was reinforced during $50 \%$ of $\mathrm{AX}$ trials and $50 \%$ of $\mathrm{BX}$ trials (i.e., $\mathrm{AX} \pm / \mathrm{BX} \pm$ where + refers to reinforced trials and - refers to nonreinforced trials). Thus, for the uncorrelated group, Stimuli A, B, and X were equally predictive of reinforcement. A second group (correlated) received training in which barpressing was reinforced on $100 \%$ of the AX trials, whereas responding during the $\mathrm{BX}$ trials was never reinforced (i.e., $\mathrm{AX}+/ \mathrm{BX}-$ ). Thus, for the correlated group, $\mathrm{A}$ was reinforced $100 \%$, B was reinforced $0 \%$, and $X$ was reinforced $50 \%$ of the time each stimulus was presented. Consequently, in contrast to the uncorrelated condition, $\mathrm{A}, \mathrm{B}$, and $\mathrm{X}$ were differential predictors of reinforcement for the correlated condition. Note that for the two groups, the absolute predictive validity of $\mathrm{X}$ within trials was equal (i.e., $50 \%$ reinforcement). However, relative to the other stimuli present during training (i.e., $\mathrm{A}$ and $\mathrm{B}$ ), $\mathrm{X}$ was a more valid predictor of reinforcement for the uncorrelated group than for the correlated group. Therefore, if the relative predictive validity of cues is important in controlling behavior, $\mathrm{X}$ should have acquired greater behavioral control in the uncorrelated than in the correlated group.

The results of Wagner et al. (1968; also see Wasserman, 1974) supported the importance of the relative pre- 
dictive validities of cues during training in controlling subsequent behavior. That is, behavioral control by $\mathrm{X}$ was greater in the uncorrelated than in the correlated group. Differences in behavioral control by $\mathrm{X}$ in the correlated and uncorrelated groups could not be explained by the overall percentage of trials during which $X$ was reinforced because $\mathrm{X}$ was reinforced on $50 \%$ of its presentations for both groups.

To account for the relative validity effect reported by Wagner et al. (1968), Wagner (1969a, 1969b) proposed a cue competition model in which stimuli compete with one another for a limited amount of associative strength supportable by a US. Wagner suggested that stimuli that are relatively less predictive of the US fail to form, or at best form a weak association, with the US. Thus, in the case of the correlated group, $X$, which had less predictive validity than $\mathrm{A}$, should have become at best weakly associated with the US and consequently should have gained little behavioral control. The Rescorla-Wagner (1972) model provides another acquisition-failure account. Given that $\beta 1$ (for reinforced trials) is greater than $\beta 2$ (for nonreinforced trials), the Rescorla-Wagner model predicts that acquisition of excitatory associative strength to $\mathrm{X}$ in the correlated group will be less than that in the uncorrelated group. For the correlated group, $X$ should acquire some associative strength on $\mathrm{AX}+$ trials. However, on $\mathrm{BX}$ - trials the associative strength of $\mathrm{X}$ should be decremented. The Rescorla-Wagner model predicts that, because $\mathrm{A}$ was more predictive of reinforcement than was $\mathrm{X}$ in the correlated group, A will progressively absorb an increasing amount of the total associative strength supportable by the US until asymptote is reached. The Rescorla-Wagner model predicts that ultimately subjects in the correlated group should stabilize with a strong excitatory A-US association and a relatively weak excitatory $\mathrm{X}$-US association. In the uncorrelated group, A, B, and $X$ should each acquire and retain moderately strong excitatory associations with the US. Nonreinforced AX and $\mathrm{BX}$ trials are predicted to prevent $\mathrm{A}$ and $\mathrm{B}$ from acquiring the majority of associative strength during training. Hence, the associative strengths of $A, B$, and $X$ are expected to fluctuate around moderate values, slightly increasing on reinforced trials and slightly decreasing on nonreinforced trials. Thus, like Wagner's stimulus selection model, the Rescorla-Wagner model predicts a more excitatory X-US association in the uncorrelated group than in the correlated group, and this difference arises because of a failure to acquire a robust X-US association in the correlated group.

Expression-failure models provide a theoretical alternative to acquisition-failure models. To explain the relative validity effect, expression-failure models assume that target CS-US associations are indeed learned, but that these associations are not expressed at the time of testing. Comparator theories, which are a class of expressionfailure models, explain cue competition by suggesting that not only the target CS, but also other stimuli present during training (e.g., the training context and nontarget punctate stimuli [such as A and B in the case of relative validity training]) form associations with the US during training. Unless the target CS is a better predictor of reinforcement than are the other stimuli present during training, comparator theories predict that subjects will fail to respond to the target CS at test. Examples of such theories include the scalar expectancy theory of Gibbon and Balsam (1981) and the comparator hypothesis of Miller and Matzel (1988; see also Miller \& Schachtman, 1985).

Regardless of how plausible each family of theorizing appears, the ultimate judge of theory is empirical evidence. Several studies have provided evidence that directly addresses the issue of acquisition-failure versus expression-failure explanations of cue competition effects. An acquisition failure should lead to performance failure that is irreversible (without further training). However, a number of different treatments (other than further CS-US training) have been found to produce an attenuation of select cue competition effects. For example, by increasing the retention interval between the termination of training and testing from days to weeks, Kraemer, Lariviere, and Spear (1988) successfully attenuated the overshadowing effect. Miller, Jagielo, and Spear (1993) have demonstrated an analogous spontaneous recovery from blocking through the use of long retention intervals.

Posttraining extinction of the competing cue has also been shown to be an effective means of attenuating some cue competition effects. For example, nonreinforced presentations of the overshadowing CS following conditioning with a compound CS results in a facilitated conditioned response to the overshadowed cue (Kaufman \& Bolles, 1981; Matzel, Schachtman, \& Miller, 1985). If the overshadowing effect were an irreversible failure to acquire the association between the overshadowed CS and the US, such results would not be observed. Of particular interest is that attenuation of the overshadowing effect through posttraining extinction was stimulus specific (Miller, Barnet, \& Grahame, 1992, Experiment 3). That is, responding to the overshadowed stimulus was not facilitated by the extinction of any arbitrary overshadowing stimulus, but only when the extinguished cue was the overshadowing stimulus for that specific stimulus.

Posttraining extinction manipulations have also been successful in attenuating the relative validity effect (Cole, Barnet, \& Miller, 1995a). Cole et al. extinguished the stimulus perfectly correlated with reinforcement in the relative validity procedure (i.e., A) and observed facilitated responding to $\mathrm{X}$ by subjects that had received correlated relative validity training. Like posttraining extinction manipulations that produced an attenuation of the overshadowing effect, the extinction manipulations that produced attenuation of the relative validity effect were also stimulus specific. That is, extinction of excitors other than the most valid predictor of reinforcement (i.e., A) that was present during training of the target stimulus (i.e., $X$ ) did not facilitate responding to $X$. Thus, the recovery from the relative validity effect reported by Cole et al, is fully explicable in terms of the comparator hypothesis. 
Experiments in which a posttraining presentation of a feature of the training episode is presented as a "reminder" prior to testing also support the suggestion that cue competition effects are failures to express previously acquired information. Such reminder treatments are typically a brief presentation of either the target CS alone or the US alone. For example, Kasprow, Cacheiro, Balaz, and Miller (1982) observed selectively enhanced responding to an overshadowed CS following reminder treatments consisting of brief exposure to that CS. Other studies have reported an amelioration of the blocking effect following reminder treatments with the US, the blocked CS, or the training context (e.g., Balaz, Gutsin, Cacheiro, \& Miller, 1982; Schachtman, Gee, Kasprow, \& Miller, 1983). Reminder treatments have also been shown to produce recovery from various other performance deficits that were initially viewed as reflecting permanent acquisition deficits, including performance deficits caused by electroconvulsive shock (e.g., Miller, Ott, Berk, \& Springer, 1974), infantile amnesia (e.g., Campbell \& Jaynes, 1966), and spontaneous forgetting (e.g., Deweer, Sara, \& Hars, 1980).

Taken together, these reports suggest that cue competition effects are not completely due to a failure to acquire the critical information of each task, but rather to some failure in memory retrieval or expression. As previously stated, the attenuation of cue competition effects without further CS-US training is inconsistent with acquisition-failure theories. Expression-failure accounts (and comparator views in particular), however, can potentially explain the available data demonstrating recovery from performance deficits seen in cue competition situations. Compared to blocking and overshadowing, however, relative validity has been largely neglected in regard to the issue of whether it reflects an irreversible deficit in acquisition or a reversible deficit in memory expression. The current experimental series was designed to extend the findings of Cole et al. (1995a), which suggested that the relative validity effect was at least in part and perhaps entirely due to a failure to express acquired information. Cole et al. used a posttraining extinction manipulation and witnessed a recovery from the relative validity performance deficit. Their data suggest that a deficit in expressing acquired information contributes to this performance deficit just as it does to the other cue competition performance deficits of blocking and overshadowing. The current experiments employed two types of reminder treatments in an attempt to further contrast acquisition-failure and expression-failure explanations of the relative validity effect in particular, and more generally cue competition.

\section{EXPERIMENT 1}

In Experiment 1 we examined the nature of the response deficit witnessed in the relative validity effect by administering a reminder treatment consisting of posttraining presentation of the US used in the original training episode. Reminder treatments (presentation of one stimulus from the original training episode) are hypoth- esized to reactivate a memory trace of the original training episode. The reactivated representation then stimulates further processing of the memory for the original event, thereby facilitating the retrieval of the original information and enhancing performance on subsequent tests (Spear, 1973). Thus, if the relative validity effect reflects a failure to express acquired information, and posttraining presentation of the US used during training acts as a reminder in the fashion hypothesized by Spear, the behavioral deficit of the relative validity effect should be attenuated by such a reminder treatment.

\section{Method}

\section{Subjects}

Twenty-four male and 24 female experimentally naive SpragueDawley rats from our own breeding colony served as subjects. Weight ranges were $312-422 \mathrm{~g}$ for males and 201-298 $\mathrm{g}$ for females. Subjects were individually housed in standard hanging, stainless-steel, wire-mesh cages in a vivarium maintained on a 16:8 light:dark cycle. Experimental manipulations occurred near the midpoint of the 16-h light cycle. The animals were allowed free access to Purina Lab Chow in their home cages. One week prior to the initiation of the study, all animals were progressively deprived of water. By Day 1 of the study, access to water in the home cage was limited to $10 \mathrm{~min}$ per day and provided $18-22 \mathrm{~h}$ prior to any treatment scheduled for the following day. All subjects were handled three times per week, for $30 \mathrm{sec}$, from the time of weaning until the initiation of the study. Subjects were randomly assigned to one of four groups $(n=12)$ : Group Correlated (Group C), Group Correlated US Reminder (Group C.US.REM), Group Uncorrelated (Group U), and Group Uncorrelated US Reminder (Group U.US.REM).

\section{Apparatus}

Two types of experimental chambers were used. Chamber $\mathrm{R}$ was rectangular in shape and measured $30.30 \times 8.25 \times 12.30 \mathrm{~cm}(1 \times \mathrm{w}$ $\times h)$. The walls and ceiling were constructed of clear Plexiglas and the floor consisted of stainless-steel rods. The rods of the floor measured $0.48 \mathrm{~cm}$ in diameter and were spaced $1.5 \mathrm{~cm}$ apart, center to center. The rods were connected through NE-2 neon bulbs, which allowed constant-current footshock to be delivered by means of a highvoltage $\mathrm{AC}$ circuit in series with a $1.0-\mathrm{M} \Omega$ resistor. Each of six copies of Chamber $\mathbf{R}$ was housed in a separate light- and soundattenuating environmental isolation chest. Chamber $\mathrm{R}$ was dimly illuminated by a $2-\mathrm{W}$ (nominal at $120 \mathrm{VAC}$ ) bulb driven at $56 \mathrm{VAC}$. The bulb was mounted on an inside wall of the environmental chest approximately $30 \mathrm{~cm}$ from the center of the experimental chamber.

Chamber $V$ was a $25.50 \mathrm{~cm}$ long box in the shape of a vertical, truncated V. The chamber was $26.20 \mathrm{~cm}$ high, $21.00 \mathrm{~cm}$ wide at the top, and narrowed to $5.25 \mathrm{~cm}$ wide at the bottom. The ceiling was constructed of clear Plexiglas and the walls were of black Plexiglas. The floor consisted of two $25.50 \mathrm{~cm}$ long parallel metal plates, each $2 \mathrm{~cm}$ wide and separated by a $1.25-\mathrm{cm}$ gap. A constant-current footshock could be delivered through the metal walls and floor of the chamber. Each of six copies of Chamber $V$ was housed in a separate light- and sound-attenuating environmental isolation chest. Chamber $\mathrm{V}$ was dimly illuminated by a 7.5 -W (nominal at $120 \mathrm{VAC}$ ) bulb driven at $56 \mathrm{VAC}$. The bulb was mounted on an inside wall of the environmental chest approximately $30 \mathrm{~cm}$ from the center of the experimental chamber. Light entered the experimental chamber primarily by reflection from the roof of the environmental chest. Despite the difference in the illuminating bulb in Chamber V, the actual light intensity inside Chamber $V$ roughly matched that in Chamber $R$ due to differences in the opaqueness of the walls of the two types of chambers. The houselights were illuminated throughout the experiment. 
Chambers $R$ and $V$ could be equipped with a water-filled lick tube. When inserted, the lick tube extended about $1 \mathrm{~cm}$ into a cylindrical drinking recess that was set into one of the narrow Plexiglas walls of the chamber (axis perpendicular to wall). Each drinking recess was left-right centered on the chamber wall, with its bottom $1.75 \mathrm{~cm}$ above the floor of the apparatus. The recess was $4.5 \mathrm{~cm}$ in diameter and $5.0 \mathrm{~cm}$ deep. An infrared photobeam was projected across the recess approximately $1 \mathrm{~cm}$ in front of the lick tube. In order to drink from the lick tube, subjects had to insert their heads into the recess and thereby break the photobeam. Thus, the times during which subjects were licking could be recorded.

Within each chamber, a visual stimulus consisting of a flashing light ( $0.20 \mathrm{sec}$ on $/ 0.20 \mathrm{sec}$ off) could be delivered. In Chamber $R$, the flashing light was provided by a $25-\mathrm{W}$ bulb; in Chamber V, the flashing light was provided by a $100-\mathrm{W}$ bulb. The bulbs were mounted on an inside wall of the experimental chests and were located approximately $30 \mathrm{~cm}$ from the center of the chamber. All chambers were also equipped with four speakers mounted on the interior walls of the environmental chest. Each speaker could deliver a different auditory stimulus, that was either a click train (6 clicks/sec), a white noise, a low tone $(300 \mathrm{~Hz})$, a high tone $(3000 \mathrm{~Hz})$, or a buzzing sound. In Experiment 1, only the click, white noise, and high tone were used. When they were presented, the auditory stimuli were each approximately $8 \mathrm{~dB}$ above the ambient background noise of $74 \mathrm{~dB}(\mathrm{C})$ SPL, which was produced primarily by a ventilation fan in each environmental enclosure.

\section{Procedure}

The critical aspects of Experiment 1 are summarized in Table 1. The click train served as $X$, and the high tone and white noise, counterbalanced, served as A and B. All CSs were $10 \mathrm{sec}$ in duration and the US was a $0.5-\mathrm{sec}, 1.0-\mathrm{mA}$ footshock. Chambers $\mathrm{R}$ and $V$, counterbalanced, served as Contexts 1 and 2.

Acclimation. Acclimation to the experimental chambers was conducted in Context 1 and Context 2 on Days 1 and 2, respectively, during 60-min sessions. During these sessions neither punctate CSs nor USs were presented and animals had access to waterfilled lick tubes.

Relative validity training. Following acclimation, the lick tubes were removed from all chambers. Training was conducted in Context 1 on Days 3-14. All sessions were $60 \mathrm{~min}$ in duration. For Groups $\mathrm{C}$ and C.US.REM (i.e., the correlated training condition), each session consisted of $6 \mathrm{AX}+$ and $6 \mathrm{BX}-$ trials, and for Groups U and U.US.REM (i.e., the uncorrelated training condition), each session consisted of three trials each of $\mathrm{AX}+, \mathrm{AX}-$, $\mathrm{BX}+$, and $\mathrm{BX}-$. Trial types were pseudo-randomly intermingled during the session with a mean intertrial interval (ITI) of $5 \mathrm{~min}$.

US reminder. On Day 15 , subjects in Groups C.US.REM and U.US.REM were administered a 6-min reminder session in Context 2 . The reminder session consisted of two 0.5 -sec presentations of the US alone; however, the intensity of the reminder shock was raised to $1.5 \mathrm{~mA}$, which preliminary research found to be

Table 1

Experiment 1 Design Summary

\begin{tabular}{lccc}
\hline & $\begin{array}{c}\text { Relative Validity } \\
\text { Training }\end{array}$ & Reminder & Test \\
\hline C & $\mathrm{AX}+/ \mathrm{BX}-$ & None & $\mathrm{X}$ \\
C.US.REM & $\mathrm{AX}+/ \mathrm{BX}-$ & + & $\mathrm{X}$ \\
U & $\mathrm{AX} \pm / \mathrm{BX} \pm$ & None & $\mathrm{X}$ \\
U.US.REM & $\mathrm{AX} \pm / \mathrm{BX} \pm$ & + & $\mathrm{X}$ \\
\hline
\end{tabular}

Note--Relative validity training and testing occurred in Context 1 . Reminder treatments occurred in Context 2 . All testing occurred in Context $1 .+$, training unconditioned stimulus (US); + , more intense reminder US; - , nonreinforced trials; \pm , trials reinforced $50 \%$ of the time; C, correlated; C.US.REM, correlated US reminder; U, uncorrelated; U.US.REM, uncorrelated US reminder. more effective than a $1.0-\mathrm{mA}$ reminder shock. Presumably, the $1.5-\mathrm{mA}$ shock was a stronger retrieval cue for the latent X-US association by virtue of some process similar to Hull's (1952) stimulus intensity dynamism. Subjects in Groups $\mathrm{C}$ and $\mathrm{U}$ remained in the home cage during these sessions, but received equivalent handling. Lick tubes were not available during the reminder session.

Reacclimation. On Days 16-17, the water-filled lick tubes were reinserted and $60-$ min reacclimation sessions similar to those conducted on Days 1-2 were administered in Context 1. These sessions were intended to reestablish a stable rate of drinking for all subjects.

Testing. On Day 18, all animals were tested in Context 1 for suppression of ongoing drinking in the presence of the target stimulus (i.e., $X$ ). During the test session, animals were allowed to drink from the lick tubes for 5 cumulative seconds, at which time the target stimulus was presented. Thus, all subjects were drinking at $\mathrm{CS}$ onset. Times to complete the first 5 cumulative seconds of licking (prior to CS onset) and an additional 5 cumulative seconds (in the presence of the target stimulus) were recorded.

Prior to statistical analysis, all suppression data were converted to $\log$ (base 10) scores to better meet the assumptions of parametric statistical analysis. A .05 alpha level was adopted for all statistical tests throughout this series of experiments.

\section{Results and Discussion}

A US reminder treatment administered after relative validity training facilitated responding to $X$ for subjects in the correlated condition, but not in the uncorrelated condition. Thus, a US reminder successfully attenuated the performance deficit of the relative validity effect.

Prior to testing, one animal from Group $\mathrm{C}$ became ill and was consequently eliminated from the experiment. A $2 \times 2$ (training condition [i.e., correlated vs. uncorrelated] $\times$ reminder condition [i.e., reminder vs. no reminder]) analysis of variance (ANOVA) was conducted. That analysis revealed an effect of training condition $[F(1,43)=$ 17.94], an effect of reminder condition $[F(1,43)=22.91]$, and a training condition $\times$ reminder condition interaction $[F(1,43)=6.19]$. Planned comparisons were conducted using the overall error term. As Figure 1 reveals, Group $\mathrm{C}$ suppressed less to $\mathrm{X}$ than did Group $\mathrm{U}[F(1,43)=$ 21.92 ], thereby demonstrating the basic relative validity deficit. Group C.US.REM showed greater suppression to $\mathrm{X}$ relative to Group $\mathrm{C}[F(1,43)=25.63]$, indicating that the presentation of the US reminder following training facilitated suppression to the target stimulus. Finally, Figure 1 shows that suppression to $X$ in Groups $U$ and U.US.REM did not differ $[F(1,43)=2.78]{ }^{1}$

The difference in suppression to $\mathrm{X}$ between Groups $\mathrm{C}$ and C.US.REM suggests that the performance deficit in the relative validity effect arose, at least in part, from Group C's failure to express information acquired during relative validity training (see also Cole et al., 1995a). The lack of effect of the reminder treatment in Group U.US.REM relative to Group U suggests that the reminderenhanced responding of Group C.US.REM was specific to subjects otherwise exhibiting the relative validity deficit. If the response-enhancing consequence of the USreminder treatment had not been specific to subjects displaying the relative validity deficit, enhanced responding would likely have been seen in both correlated and uncorrelated reminder groups. Notably, the lack of enhanced 


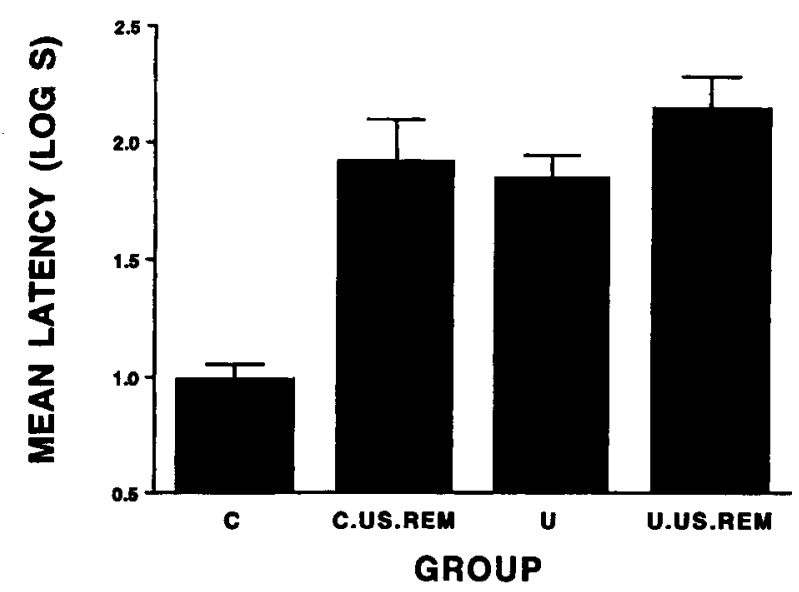

Figure 1. Mean latencies in Experiment 1 for Groups Correlated (C), Correlated US Reminder (C.US.REM), Uncorrelated (U), and Uncorrelated US Reminder (U.US.REM) to complete 5 cumulative seconds of licking in the presence of $X$. Error bars denote standard errors of the mean.

responding in Group U.US.REM was not due to a ceiling effect, since the mean time to complete 5 cumulative seconds of drinking was substantially below the imposed ceiling of $2.95 \log \mathrm{sec}(15 \mathrm{~min})$. Thus, the facilitation in responding to $\mathrm{X}$ observed in Group C.US.REM without further CS-US training, indicates that these animals had successfully acquired the target stimulus-US association during training. The results of Experiment 1 are incongruent with acquisition-failure theories of conditioning. If the $\mathrm{X}-\mathrm{US}$ association was not acquired by subjects in the correlated condition during training, then a presentation of the US alone should not have selectively facilitated responding to $\mathrm{X}$ in only the correlated condition.

\section{EXPERIMENT 2}

Experiment 2 was designed to further evaluate the effectiveness of reminder treatments in alleviating the performance deficit seen in the relative validity effect. In Experiment 1 we examined (1) the effects of presenting the US as a reminder treatment after relative validity training; (2) the effect of CS reminder treatment after relative validity training on responding to the target stimulus (X), and (3) the issue of the stimulus specificity of CS reminder treatments by providing relative validity training for two distinct target stimuli, $\mathrm{X}$ and $\mathrm{Y}$. If reminders selectively activate the original learning episode, as hypothesized by Spear (1973), one would expect that the presentation of an arbitrary CS (other than the target CS) would not affect responding to the target CS. That is, a reminder event from the original training episodes of one target CS should enhance responding to that target stimulus, but not a second target stimulus.

\section{Method}

\section{Subjects}

Twenty-four male and 24 female experimentally naive SpragueDawley rats from our own breeding colony served as subjects. Subjects were randomly assigned to one of four groups $(n=12)$ : Groups Correlated (C), Correlated CS Reminder (C.CS.REM), Uncorrelated (U), and Uncorrelated CS Reminder (U.CS.REM). Weight ranges were 298-412 $\mathrm{g}$ for males and 210-324 $\mathrm{g}$ for females. Subjects were housed and maintained as in Experiment 1.

\section{Apparatus}

The apparatus and stimuli used in Experiment 2 were the same as those in Experiment 1 except where otherwise noted.

\section{Procedure}

The critical aspects of the procedure are summarized in Table 2. Stimuli $X$ and $Y$ were the click train $(6 / \mathrm{sec})$ and buzzer, counterbalanced within groups. Symbolic stimulus pairs $A$ and $B$ and $G$ and $\mathrm{H}$ were two pairs of physical stimuli: a high-frequency tone $(3000 \mathrm{~Hz})$ and white noise, and a low-frequency tone $(300 \mathrm{~Hz})$ and a flashing light (.2 sec on/.2 sec off), counterbalanced between the two symbolic pairs and within the symbolic elements. Contexts 1 and 2 were Chambers $R$ and V, counterbalanced. Context 3 was Chamber $R$ with the addition of an odor cue (methyl salicylate), Plexiglas floor plates, and a decrease in chamber illumination (i.e., houselight off).

Acclimation. Acclimation to the experimental chambers was conducted in Context 1 on Days 1 and 4 , in Context 2 on Days 2 and 5 , and in Context 3 on Days 3 and 6. During these 30-min sessions, neither CSs nor USs were presented and all animals had access to water-filled lick tubes.

Relative validity training. Following acclimation, the lick tubes were removed from all chambers. On Days 7--30, subjects in Groups C and C.CS.REM (i.e., the correlated treatment condition) were administered a 60 -min session in Context 1 during which $6 \mathrm{AX}+$ and $6 \mathrm{BX}-$ trials occurred on even-numbered days, and a 60-min session in Context 2 during which $6 \mathrm{GY}+$ and $6 \mathrm{HY}-$ trials occurred on odd-numbered days. On Days $7-30$, subjects in Group U and U.CS.REM (i.e., the uncorrelated treatment condition) were administered a 60 -min session in Context 1 during which three trials each of $\mathrm{AX}+, \mathrm{AX}-, \mathrm{BX}+$, and $\mathrm{BX}$ - occurred on evennumbered days, and a 60-min session in Context 2 during which three trials each of GY+, GY-, HY+, and $\mathrm{HY}$ - occurred on oddnumbered days. Trial types within a session were pseudorandomly interspersed with a mean ITI of $5 \mathrm{~min}$.

Table 2

Experiment 2 Design Summary

\begin{tabular}{lcccc}
\hline \multicolumn{1}{c}{ Group } & Relative Validity Training & Reminder & Test 1 & Test 2 \\
\hline C & {$[\mathrm{AX}+/ \mathrm{BX}-]_{1}[\mathrm{GY}+/ \mathrm{HY}-]_{2}$} & None & {$[\mathrm{X}]_{1}$ or $[\mathrm{Y}]_{2}$} & {$[\mathrm{Y}]_{2}$ or $[\mathrm{X}]_{1}$} \\
C.CS.REM & {$[\mathrm{AX}+/ \mathrm{BX}-]_{1}[\mathrm{GY}+/ \mathrm{HY}-]_{2}$} & {$[\mathrm{X}-]_{3}$} & {$[\mathrm{X}]_{1}$ or $[\mathrm{Y}]_{2}$} & {$[\mathrm{Y}]_{2}$ or $[\mathrm{X}]_{1}$} \\
$\mathrm{U}$ & {$[\mathrm{AX} \pm / \mathrm{BX} \pm]_{1}[\mathrm{GY} \pm / \mathrm{HY} \pm]_{2}$} & None & {$[\mathrm{X}]_{1}$ or $[\mathrm{Y}]_{2}$} & {$[\mathrm{Y}]_{2}$ or $[\mathrm{X}]_{1}$} \\
U.CS.REM & {$[\mathrm{AX} \pm / \mathrm{BX} \pm]_{1}[\mathrm{GY} \pm / \mathrm{HY} \pm]_{2}$} & {$[\mathrm{X}-]_{3}$} & {$[\mathrm{X}]_{1}$ or $[\mathrm{Y}]_{2}$} & {$[\mathrm{Y}]_{2}$ or $[\mathrm{X}]_{1}$} \\
\hline
\end{tabular}

Note -[]$_{1},[]_{2}$, and []$_{3}$, Contexts 1,2 , and 3, respectively; A, B, G, and $H$, the nontarget stimuli, and $X$ and $Y$ represent the target stimuli; + , the $U S ;-$, nonreinforced trials;, $\pm 50 \%$ reinforcement; C, correlated; C.CS.REM, correlated CS reminder; U, uncorrelated; U.CS.REM, uncorrelated CS reminder. 
CS reminder. On Day 31, subjects in Groups C.CS.REM and U.CS.REM were administered a 6 -min reminder session in Context 3. The reminder session consisted of two 10-sec nonreinforced presentations of $X$. Subjects in Groups $C$ and $U$ remained in the home cage during these sessions, but received equivalent handling. Lick tubes were not available during the reminder session.

Reacclimation. On Days 32-33, the water-filled lick tubes were reinserted and daily $30-\mathrm{min}$ reacclimation sessions similar to those conducted on Days 1-6 were administered in Context 1 for half the subjects in each group and Context 2 for the remaining subjects.

Testing. On Day 34, the subjects reacclimated to Context 1 on Days 32 and 33 were tested in Context 1 for suppression of ongoing drinking in the presence of $X$. The remaining subjects were tested for suppression to $\mathrm{Y}$ in Context 2 . Testing was procedurally identical to that of Experiment 1 except that all test CSs remained on for a fixed duration of $15 \mathrm{~min}$ in order to equate duration of exposure to the target stimulus, thereby not providing differential treatment that could affect performance on any subsequent test.

Reacclimation. On Days 35-36, the water-filled lick tubes were reinserted and daily 30 -min reacclimation sessions similar to those conducted on Days 1-6 were administered in Context 2 if Day 34 testing had occurred in Context 1 , and Context 1 if Day 34 testing had occurred in Context 2.

Testing. On Day 37, subjects were tested in the context to which they had been reacclimated on Days 35 and 36 . Subjects previously tested on $\mathrm{X}$ were now tested on $\mathrm{Y}$, and vice versa. With the exception of the test stimulus used, testing on Day 37 was procedurally identical to that conducted on Day 34. As in Experiment 1, all suppression data were converted to $\log$ (base 10 ) scores.

\section{Results and Discussion}

The CS reminder treatment was effective in attenuating the relative validity deficit. Additionally, facilitation of responding to the target stimulus was stimulus specific.

Prior to testing, one subject from Group U became ill and was eliminated from the experiment. A mixed $2 \times 2 \times$ 2 (training condition [i.e., correlated vs. uncorrelated] $\times$ test stimulus [i.e., $\mathrm{X}$ vs. $\mathrm{Y}$ ] $\times$ reminder condition [i.e., reminder vs. no reminder]) ANOVA was conducted, with the test stimulus factor being within subject. This analysis revealed an effect of training condition $[F(1,43)=$ $39.28]$, an effect of reminder condition $[F(1,43)=4.99]$, an effect of test stimulus $[F(1,43)=9.74]$, and a training condition $\times$ test stimulus interaction $[F(1,43)=9.00]$. Planned comparisons were conducted. Figure 2 illustrates mean suppression to $\mathrm{X}$ and $\mathrm{Y}$ for the various groups of Experiment 2. Lower suppression to $\mathrm{X}$ and $\mathrm{Y}$ by Group $\mathrm{C}$ than by Group $\mathrm{U}[F(1,43)=10.47$ and $F(1,43)=26.91$, respectively] demonstrates the basic relative validity deficit in the two separate discriminations. Greater suppression to $\mathrm{X}$ by Group C.CS.REM relative to Group C $[F(1,43)=12.35]$ demonstrates an attenuation of the relative validity deficit as a result of administration of the CS reminder treatment. The failure to observe a difference in suppression to $\mathrm{Y}$ between Groups C.CS.REM and $C[F(1,43)=0.54]$, indicates that the facilitation of suppression to $\mathrm{X}$ in Group C.CS.REM was not produced by the presentation of any arbitrary CS reminder, but rather, facilitation of $X$ was produced specifically by presentation of X. Groups U and U.CS.REM did not respond differentially to $\mathrm{X}[F(1,43)=0.38]$, or $\mathrm{Y}[F(1,43)=$ $0.00]$. Thus, the benefit of the CS reminder treatment was

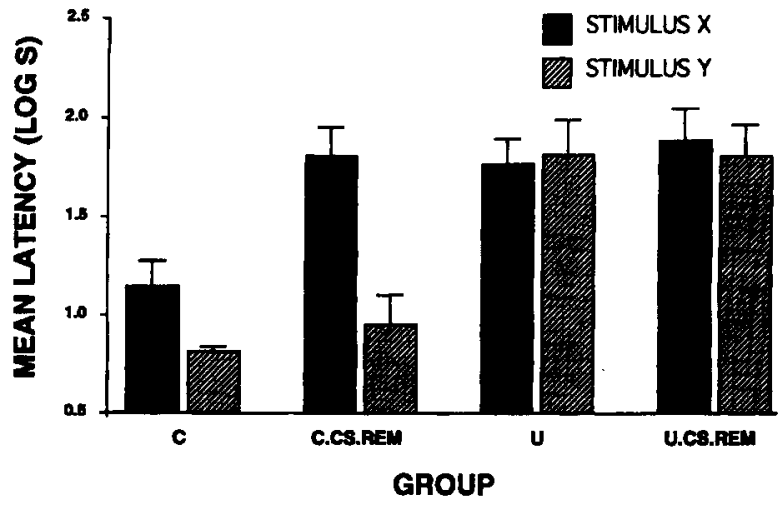

Figure 2. Mean latencies in Experiment 2 for Groups Correlated (C), Correlated CS Reminder (C.CS.REM), Uncorrelated (U), and Uncorrelated CS Reminder (U.CS.REM) to complete 5 cumulative seconds of licking in the presence of Stimuli $X$ and $Y$. Error bars denote standard errors of the mean.

limited to subjects that would otherwise have exhibited the relative validity deficit (i.e., the correlated condition).$^{2}$ Although reminder (i.e., cuing) manipulations have frequently been used to facilitate responding in animals after various treatments that attenuate behavior (including blocking, overshadowing, CS preexposure, interference, and extinction), to our knowledge this is the first study to demonstrate clear stimulus specificity of the facilitory effect of reminder treatments using for control purposes another cue for which responding was impaired similarly to the target cue.

The differential suppression to $\mathrm{X}$ by Groups $\mathrm{C}$ and C.CS.REM further supports the view that the performance deficit in the relative validity effect is due, at least in part, to a failure on the part of subjects in Group $C$ to express acquired information about $\mathrm{X}$ (see also Cole et al., 1995a). Because no further X-US training occurred following the original training episode, and subjects in Group C.CS.REM showed facilitated responding to $\mathrm{X}$ (relative to Group $\mathrm{C}$ ), the enhanced responding observed in Group C.CS.REM suggests that Group C acquired a latent $\mathrm{X}-\mathrm{US}$ association. This argues against the position of acquisition-failure models that subjects in Group C.CS.REM failed to acquire an X-US association. As in Experiment 1, the lack of influence of the reminder treatment on uncorrelated subjects is consistent with the view that correlated training resulted in a latent $\mathrm{X}$-US association that was lacking in the uncorrelated subjects. Again, the scores of the uncorrelated subjects were sufficiently below the imposed ceiling $(2.95 \log \mathrm{sec})$ to preclude the possibility of a ceiling effect masking reminder-induced enhanced suppression in uncorrelated subjects.

\section{GENERAL DISCUSSION}

The results of the present research provide further support for the suggestion advanced by Cole et al. (1995a) that the performance deficit constituting the relative va- 
lidity effect arises in large part from a failure to express acquired information. As a result of posttraining extinction of the reinforced companion stimulus (A in our notation), Cole et al. observed an attenuation of the relative validity effect. The present research employed reminder treatments and also witnessed recovery from the relative validity effect. Note that neither the recovery manipulations employed by Cole et al. nor those of the present studies exposed animals to any target CS-US pairings (i.e., $\mathrm{X}$-US) following relative validity training, thereby precluding the possibility that any relevant new target CS-US learning affected test performance. Therefore, the relative validity effect appears not to arise entirely from a failure to acquire the critical X-US association, but rather from a failure to express it. However, advancing the conclusion that the relative validity effect, like blocking and overshadowing, is due in large part to a failure to express acquired information must be done with some degree of caution. That posttraining treatments such as reminder presentations improve performance in cue competition situations does not directly speak to why performance was otherwise deficient without the posttraining manipulations. Additionally, our results add to a more general body of evidence suggesting that reminder treatments are an effective means of revealing latent associations in various experimental situations (e.g., blocking, Balaz et al., 1982; overshadowing, Kasprow et al., 1982; infantile amnesia, Campbell \& Jaynes, 1966; spontaneous forgetting, Deweer et al., 1980; electroconvulsive shock, Miller et al., 1974; extinction, Schachtman et al., 1983; latent inhibition, Kasprow, Catterson, Schachtman, \& Miller, 1984; and acquisition curves, Miller, 1982).

The present research also addressed the stimulus specificity of recovery from the relative validity effect. We can discount explanations of reminder-induced recovery suggesting that reminder treatments generally increase performance given an initial low level of responding (independent of why it is low) because posttraining exposure to $\mathrm{X}$ in Experiment 2 did not facilitate responding to $\mathrm{Y}$ in Group C.CS.REM. Moreover, the robust responding of Group C.CS.REM to $X$ relative to $Y$ (which shared a comparable training history with $\mathrm{X}$ ) indicates that posttraining exposure to any arbitrary stimulus is not sufficient in promoting recovery from the relative validity effect. It appears that a reminder treatment consisting of a specific target stimulus selectively enhances responding to that stimulus. However, one might contend that our CS reminder treatment confounded exposure to Context 3 , thus not allowing us to pinpoint the source of the witnessed recovery. But, it is implausible that exposure to Context 3 critically enhanced the behavioral control exerted by $\mathrm{X}$ in Group C.CS.REM because responding to $\mathrm{Y}$ in this group did not improve despite identical exposure to Context 3 . Thus, the results of Experiment 2 indicate a stimulus specificity of the CS reminder treatments.

In our interpretation of the current data, we contend that the relative validity effect, like the cue competition effects of blocking and overshadowing, is in large part due to a reversible performance deficit rather than to a failure to acquire information. That is, we propose that reminder treatments increase sensitivity in measuring the information subjects had acquired during training. However, one could potentially argue that reminder treatments do not increase sensitivity in measuring learned information, but rather decrease the sensitivity of measuring acquired information. For example, in the present experiments, reminder treatments may act to effectively mask differentially acquired information in subjects trained with correlated and uncorrelated relative validity discriminations. We find this alternative explanation of the current data implausible partly because there is no obvious mechanism that would produce such an effect. For example, in Experiment 1, if US reminders had been administered in Context 1 one could potentially argue that these reminders could have led to strengthened Context 1-US associations, which might have led to increased responding to $\mathrm{X}$. Alternatively, one might suggest that US reminders produced a nonassociative motivational change. But either of these alternatives would additionally need to provide an account of the failure of US reminders to facilitate responding to $X$ in Group U.US. REM in Experiment 1 (i.e., the proposed masking of, or decreased sensitivity in detecting, underlying associative differences between groups), the most obvious of which would be a ceiling effect. However in Experiment 1, US reminders were administered in a novel context (rather than in the training context) and ceiling effects were not observed in the conditioned responding of any groups. Thus, how US reminders administered in a novel context could depress our ability to detect associative differences between groups trained with a correlated and an uncorrelated relative validity discrimination is not obvious. Additionally, there is even less of a rationale to expect that a CS reminder might mask real differences in acquisition between the two conditions. Yet, the present data do not categorically preclude such an interpretation.

The present results are problematic for the previously mentioned models that view cue competition (the relative validity effect in particular) as an acquisition deficit. Conversely, these results are consistent with the view that much or all cue competition arises from information processing that occurs at the time of testing. Two such frameworks that capture the latter view are the interference model of Bouton (1993) and the comparator hypothesis of Miller and Matzel (1988). Bouton emphasizes interference between memories of similar events differing in terms of their outcomes (e.g., acquisition and extinction). In contrast, the comparator hypothesis emphasizes competition between dissimilar memories initially acquired during the same training event. Although both models emphasize latent associations, to date Bouton's interference model has not been developed to address cue competition, whereas the comparator hypothesis has. Specifically, it attributes cue competition effects to the high associative status of nontarget cues that are present during training of the target cue. Thus, the comparator hypothesis is readily able to explain the recovery from the relative validity effect obtained by Cole et al. (1995a) 
when they extinguished the more valid cue (A). However, the comparator hypothesis does not provide any explanation of specifically why reminder treatments are an effective means of attenuating cue competition deficits. Although the comparator hypothesis predicts that there will be a latent $\mathrm{X}$-US association in the correlated condition, it offers no mechanism to explain why reminder treatments reveal these otherwise latent associations. To correct this deficiency, the comparator hypothesis might be extended to incorporate principles about how the retrievability of the X-US, X-A, and A-US associations change with reminder treatments. But at this time, such rules are not obvious. Thus, no clear prediction can be made. In summary, the present data should be viewed as consistent with, but not highly supportive of, the comparator hypothesis. Our current view of the efficacy of reminder treatments is that they are highly salient retrieval cues that activate ordinarily latent associations. Once activated, the subsequent retrieval of these associations is enhanced (see Miller, Kasprow, \& Schachtman, 1986).

Turning to a more empirical issue, it should be noted that the reminder treatments in the present experiments were effective even with testing occurring $72 \mathrm{~h}$ after the reminder. Some researchers have found reminder effects wane with time (e.g., Feldman \& Gordon, 1979), whereas other researchers have found reminder effects to be enduring (e.g., Miller \& Springer, 1972). The present data are more consistent with reminder effects enduring long after treatment. However, none of the studies that found enduring effects of reminder treatments also used short retention intervals. Hence, the benefit of reminder treatments may in fact wane with time, but under selected circumstances (yet to be specified), the rate of this waning may be quite slow.

The results of Cole et al. (1995a) and the current experiments are representative of a larger body of research focused on the acquisition versus expression issue in cue competition. Studies examining blocking (e.g., Balaz et al., 1982; Miller et al., 1993) and overshadowing (Kasprow et al., 1982; Kaufman \& Bolles, 1981; Kraemer et al., 1988; Matzel et al., 1985) have advanced conclusions similar to those of Cole et al. and the present research concerning relative validity. The response deficits resulting from each of these three cue competition procedures appear to be reversible without further training. Hence, the acquisition failure models' explanations of cue competition appear to be either incorrect or in need of some modification that views their mechanisms as impacting expression rather than the acquisition of information. For example, the Rescorla-Wagner (1972) model might be revised so that surprise (i.e., lambda minus the predictive value of all cues present on a trial) is necessary for subsequent retrieval of an association, with predictive value being a function of readily retrievable associations rather than all associations to the cues present on that trial. Obviously, the details of such a drastic revision would have to be carefully formulated.

Learning theorists were alerted to the difference between learning and the expression of learned informa- tion well over 60 years ago (e.g., Tolman, 1932). Although some early learning theorists were concerned with performance variables (e.g., Hull, 1952), contemporary theorizing has been characterized by a general avoidance of the distinction between expression of acquired information and learning per se. The S-R theorizing of Thorndike (1898) no doubt gave rise to this bias. The rise of logical positivism and behaviorism helped to maintain the bias and to support the subsequent acceptance of theorizing, suggesting that associative strength directly maps onto observable behavior (for a more complete view of the history of the neglect of memory expression, see Spear, 1978). One need only examine the fundamental assumptions of most major theories of conditioning to see a bias toward viewing performance failures as acquisition failures (see, e.g., Hawkins \& Kandel, 1984; Mackintosh, 1975; Pearce, 1987; Pearce \& Hall, 1980; Rescorla \& Wagner, 1972; Thompson, 1986). Much is said about the conditions necessary for acquisition of information and comparatively less is said about the conditions necessary for the expression of acquired information. It is generally assumed that, once information has been acquired, presentation of retrieval cues will suffice to elicit conditioned responding. Specifically, the influence of this bias can be seen on the theoretical accounts of cue competition advanced by these models. These theories collectively posit (albeit each through a different mechanism) that cue competition effects are the result of a failure to acquire information. Such a position is clearly at odds with the body of literature cited above and in its own right is not supported by strong empirical evidence.

The continuing study of conditioning phenomena has found that numerous performance deficits, above and beyond those arising from cue competition, are due to deficiencies in postacquisition information processing (e.g., retrieval, response generation). There are abundant examples using a variety of treatments that support such a conclusion. For example: (1) Reminder treatments have proven successful in revealing latent associations in several paradigms, including reinstatement of conditioned taste aversions following extinction (Schachtman, Brown, \& Miller, 1985); reinstatement of audiovisual CSs following extinction (Bouton, 1990; Bouton \& Bolles, 1979; Rescorla \& Heth, 1975); the CS preexposure effect (Kasprow et al., 1984); performance failures caused by electroconvulsive shock (Miller et al., 1974); infantile amnesia (Campbell \& Jaynes, 1966); and spontaneous forgetting (Deweer et al., 1980). (2) Long retention intervals between training and testing have produced attenuation of extinction (Pavlov, 1927) and the CS preexposure effect (Kraemer, Randall, \& Carbary, 1991). (3) Posttraining extinction manipulations have successfully revealed latent associations in the CS preexposure effect (Grahame, Barnet, Gunther, \& Miller, 1994) and the US preexposure effect (Matzel, Brown, \& Miller, 1987). (4) Second-order conditioning procedures have been observed to promote the expression of otherwise unexpressed learning in simultaneous conditioning (Barnet, Arnold, \& Miller, 1991; 
Rescorla, 1980) and trace conditioning deficits (Cole, Barnet, \& Miller, 1995b). (5) Sensory preconditioning experiments have shown that performance deficits in simultaneous and backward conditioning (Matzel, Held, \& Miller, 1988) and trace conditioning (Cole et al., 1995b) are not entirely due to acquisition failures.

Expression failure accounts of cue competition are congruent with a compelling line of theorizing provided by Marr (1976; see also Miller et al., 1986). Marr introduced several design principles for the organization of intelligent systems. One of Marr's design principles, the principle of least commitment, states that an intelligent system should delay as long as possible any decision that commits the system irreversibly to any one course of information processing. This is so because a system irrecoverably committed to a particular processing strategy is exposed to the potential liability associated with not having access to the range of strategies and information that would be otherwise available without such a commitment. Marr's contentions, although directed toward the processing of visual information, can be reasonably viewed as an important consideration in general information processing. In the case of cue competition effects, an organism committed to a strategy of information processing that only allows learning concerning the most predictive cue present during training incurs the potential liability of not having learned about other cues that would be valuable if circumstances should change and the initially more predictive cue were absent over a series of trials. A prior failure to learn about less predictive cues would necessitate the subject's learning anew about this cue, whereas prior learning with only a failure to express the knowledge should result in the cue's later coming to control behavior at a facilitated rate. In this framework, cue competition presumably occurs because the subject's capacity to process the more valid cue during training would suffer if greater attention or processing of the less valid cue occurred.

Conditioning theories that emphasize behavioral differences as a function of differences in acquisition processes (e.g., encoding and attention) would appear to need modification to account for the evidence suggesting that conditioning phenomena such as cue competition (i.e., overshadowing, blocking, and the relative validity effect) as well as other performance deficits are mediated primarily by failure to express acquired information. On the other hand, theories that stress postacquisition processes (e.g., retrieval and expression) appear better able to account for the available empirical evidence concerning many conditioning phenomena. As Spear, Miller, and Jagielo (1990) wisely suggested, theorists should use caution in their modeling of conditioning processes until future research can elucidate how various performance deficits might be explained by failures to express acquired information, or, more precisely, how much of each effect can be attributed to variation in what information is expressed. We agree with Spear et al. that it is difficult to imagine a more important issue for the evaluation of theories of conditioning.

\section{REFERENCES}

Balaz, M. A., Gutsin, P., Cacheiro, H., \& Miller, R. R. (1982). Blocking as a retrieval failure: Reactivation of associations to a blocked stimulus. Quarterly Journal of Experimental Psychology, 34B, 99-113.

Barnet, R. C., Arnold, H. M., \& Miller, R. R. (1991). Simultaneous conditioning demonstrated in second-order conditioning: Evidence for similar associative structure in forward and simultaneous conditioning. Learning \& Motivation, 22, 253-268.

Bouton, M. E. (1990). Context and retrieval in extinction and in other examples of interference in simple associative learning. In $\mathrm{L}$. W. Dachowski \& C. F. Flaherty (Eds.), Current topics in animal learning: Brain, emotion, and cognition (pp. 25-53). Hillsdale, NJ: Erlbaum. Bouton, M. E. (1993). Context, time, and memory retrieval in interference paradigms of Pavlovian learning. Psychological Bulletin, 114, 80-99.

Bouton, M. E., \& Bolles, R. C. (1979). Role of conditioned contextual stimuli in reinstatement of extinguished fear. Journal of Experimental Psychology: Animal Behavior Processes, 15, 43-52.

CAMpbell, B. A., \& JaYNes, J. (1966). Reinstatement. Psychological Review, 73, 478-480.

Cole, R. P., Barnet, R. C., \& Miller, R. R. (1995a). Relative validity effect: Learning or performance deficit. Journal of Experimental Psychology: Animal Behavior Processes, 21, 293-303.

Cole, R. P., Barnet, R. C., \& MiLler, R. R. (1995b). Temporal encoding in trace conditioning. Animal Learning \& Behavior, 23, 144-153.

Deweer, B., Sara, S. J., \& Hars, B. (1980). Contextual cues and memory retrieval in rats: Alleviation of forgetting by pretest exposure to background stimuli. Animal Learning \& Behavior, 8, 265272 .

Feldman, D. T., \& Gordon, W. C. (1979). The alleviation of shortterm retention decrements with reactivation. Learning \& Motivation, 10, 198-210.

GibBon, J., \& BALSAM, P. (1981). Spreading association in time. In C. M. Locurto, H. S. Terrace, \& J. Gibbon (Eds.), Autoshaping and conditioning theory (pp. 219-253). New York: Academic Press.

Grahame, N. J., Barnet, R. C., Gunther, L. M., \& Miller, R. R. (1994). Latent inhibition as a performance deficit resulting from CS-context associations. Animal Learning \& Behavior, 22, 395-408.

HAWKINS, R. D., \& KANDEL, E. R. (1984). Is there a cell-biological alphabet for simple forms of learning? Psychological Review, 91, 375-391.

HuLl, C. L. (1952). A behavior system. New Haven, CT: Yale University Press.

KAMIN, L. J. (1969). Selective association and conditioning. In N. J. Mackintosh \& W. K. Honig (Eds.), Fundamental issues in associative learning (pp. 42-64). Halifax, NS: Dalhousie University Press.

Kasprow, W. J., Cacheiro, H., Balaz, M. A., \& Miller, R. R. (1982). Reminder-induced recovery of associations to an overshadowed stimulus. Learning \& Motivation, 13, 155-166.

Kasprow, W. J., Catterson, D., Schachtman, T. R., \& Miller, R. R. (1984). Attenuation of latent inhibition by post-acquisition reminder. Quarterly Journal of Experimental Psychology, 36B, 53-63.

KAUfMAN, M. A., \& Bolles, R. C. (1981). A nonassociative aspect of overshadowing. Bulletin of the Psychonomic Society, 18, 318-320.

Kraemer, P. J., Lariviere, N. A., \& SPEar, N. E. (1988). Expression of a taste aversion conditioned with an odor-taste compound: Overshadowing is relatively weak in weanlings and decreases over a retention interval in adults. Animal Learning \& Behavior, 16, 164-168.

Kraemer, P. J., Randall, C. K., \& Carbary, T. J. (1991). Release from latent inhibition with delayed testing. Animal Learning \& Behavior, 19, 139-145.

Mackintosh, N. J. (1975). A theory of attention: Variations in the associability of stimuli with reinforcement. Psychological Review, 82, 276-289.

MACKInTOSH, N. J. (1976). Overshadowing and stimulus intensity. Animal Learning \& Behavior, 4, 186-192.

MarR, D. (1976). Early processing of visual information. Transactions of the Royal Society of London, 275B, 483-519.

Matzel, L. D., Brown, A. M., \& Miller, R. R. (1987). Associative effects of US preexposure: Modulation conditioned responding by 
an excitatory training context. Journal of Experimental Psychology: Animal Behavior Processes, 13, 65-72.

Matzel, L. D., Held, F. P., \& Miller, R. R. (1988). Information and expression of simultaneous and backward associations: Implications for contiguity theory. Learning \& Motivation, 19, 317-344.

Matzel, L. D., Schachtman, T. R., \& Miller, R. R. (1985). Recovery of an overshadowed association achieved by extinction of the overshadowing stimulus. Learning \& Motivation, 16, 398-412.

Miller, J. S., Jagielo, J. A., \& SpEAR, N. E. (1993). The influence of retention interval on the US preexposure effect: Changes in contextual blocking over time. Learning \& Motivation, 24, 376-394.

MILLER, R. R. (1982). Effects of intertrial reinstatement of training stimuli on complex maze learning in rats: Evidence that "acquisition" curves reflect more than acquisition. Journal of Experimental Psychology: Animal Behavior Processes, 8, 86-109.

Miller, R. R., Barnet, R. C., \& Grahame, N. J. (1992). Responding to a conditioned stimulus depends on current associative status of other cues present during the training of that specific stimulus. Journal of Experimental Psychology: Animal Behavior Processes, 18, 251-264.

Miller, R. R., Kasprow, W. J., \& Schachtman, T. R. (1986). Retrieval variability: Sources and consequences. American Journal of Psychology, 99, 145-218.

MilleR, R. R., \& MATZEL, L. D. (1988). The comparator hypothesis: A response rule for the expression of associations. In G. H. Bower (Ed.), The psychology of learning and motivation (Vol. 22, pp. 5192). San Diego, CA: Academic Press.

Miller, R. R., Ott, C. A., Berk, A. M., \& Springer, A. D. (1974). Appetitive memory restoration after electroconvulsive shock in the rat. Journal of Comparative \& Physiological Psychology, 87, 717 . 723.

Miller, R. R., \& SChachtman, T. R. (1985). Conditioning context as an associative baseline: Implications for response generation and the nature of conditioned inhibition. In R. R. Miller \& N. E. Spear (Eds.), Information processing in animals: Conditioned inhibition (pp. 51-88). Hillsdale, NJ: Erlbaum.

MILLER, R. R., \& SPRINGER, A. D. (1972). Induced recovery of memory in rats following electroconvulsive shock. Physiology \& Behavior, 8, 645-651.

Pavlov, I. P. (1927). Conditioned reflexes (G. V. Anrep, Trans.). London: Oxford University Press.

Pearce, J. M. (1987). A model for stimulus generalization in Pavlovian conditioning. Psychological Review, 94, 61-73.

Pearce, J. M., \& Hall, G. (1980). A model for Pavlovian learning: Variations in the effectiveness of conditioned but not of unconditioned stimuli. Psychological Review, 6, 532-552.

RescoRla, R. A. (1980). Second-order conditioning. Hillsdale, NJ: Erlbaum.

Rescorla, R. A., \& Heth, C. D. (1975). Reinstatement of fear to an extinguished conditioned stimulus. Journal of Experimental Psychology: Animal Behavior Processes, 1, 88-96.

RESCORLA, R. A., \& WAGNER, A. R. (1972). A theory of Pavlovian conditioning: Variations in the effectiveness of reinforcement and nonreinforcement. In A. H. Black \& W. F. Prokasy (Eds.), Classical conditioning II: Current research and theory (pp. 64-99). New York: Appleton-Century-Crofts.

Schachtman, T. R., Brown, A. M., \& Miller, R. R. (1985). Reminderinduced recovery of a taste- $\mathrm{LiCl}$ association following extinction. Animal Learning \& Behavior, 13, 223-227.

Schachtman, T. R., GeE, J. L., Kasprow, W. J., \& Miller, R. R. (1983). Reminder-induced recovery from blocking as a function of the number of compound trials. Learning \& Motivation, 14, 154-164.
SPEAR, N. E. (1973). Retrieval of memory in animals. Psychological Review, 80, 163-194.

SPEAR, N. E. (1978). The processing of memories: Forgetting and retention. Hillsdale, NJ: Erlbaum.

SPEar, N. E., Miller, J. S., \& Jagielo, J. (1990). Animal memory and learning. Annual Review of Psychology, 41, 169-211.

Thомpson, R. F. (1986). The neurobiology of learning and memory. Science, 233, 941-947.

THORNDIKE, E. L. (1898). Animal intelligence: An experimental study of the associative processes in animals. Psychological Review, Monograph Supplement, 2(8).

Tolman, E. C. (1932). Purposive behavior in animals and men. New York: Appleton-Century-Crofts.

WAGNER, A. R. (1969a). Stimulus-selection and a "modified contiguity theory." In G. H. Bower \& J. T. Spence (Eds.), The psychology of learning and motivation (Vol. 3, pp. 1-41). New York: Academic Press.

WAGNER, A. R. (1969b). Stimulus validity and stimulus selection in associative learning. In N. J. Mackintosh \& W. K. Honing (Eds.), Fundamental issues in associative learning (pp. 90-122). Halifax, NS: Dalhousie University Press.

Wagner, A. R., Logan, F. A., Haberlandt, K., \& Price, T. (1968). Stimulus selection in animal discrimination learning. Journal of Experimental Psychology, 76, 171-180.

WASSERMAN, E. A. (1974). Stimulus-reinforcer predictiveness and selective discrimination learning in pigeons. Journal of Experimental Psychology, 103, 284-297.

\section{NOTES}

1. Although the log transformation yielded relatively Gaussian distributions within groups and allowed us to meet the assumptions of parametric statistical analysis, the possibility remains that the transformation may have distorted our means by weighting the behavior of animals with short latencies more heavily than those with long latencies. Therefore, the data from Experiment 1 were also analyzed using a series of Mann-Whitney $U$ tests. These analyses revealed greater conditioned suppression to $\mathrm{X}$ in Group $\mathrm{U}$ than in Group $\mathrm{C}(U=0.00$, $p<.01$ ), greater conditioned suppression to $\mathrm{X}$ in Group C.US.REM relative to Group $\mathrm{C}(U=13.00, p<.01)$, and equivalent conditioned suppression in Groups $\mathrm{U}$ and U.US.REM $(U=46.00, p=.13)$. Thus, the observed pattern of results in Experiment 1 was not a function of our response measure (i.e., time vs. $\log$ time) or our use of a parametric statistical test.

2. The data from Experiment 2 were also analyzed using a series of Mann-Whitney $U$ tests. With respect to the data measuring conditioned suppression to $X$, these analyses revealed greater conditioned suppression in Group $U$ than in Group $\mathrm{C}(U=20.00, p<.01)$, greater suppression in Group C.CS.REM than in Group C $(U=21.00, p<$ $.01)$, and equivalent conditioned suppression in Groups $U$ and U.CS.REM ( $U=48.00, p=.28$ ). With respect to the data measuring conditioned suppression to $Y$, these analyses revealed greater conditioned suppression in Group $\mathrm{U}$ than in Group $\mathrm{C}(U=0.00, p<.01)$, equivalent conditioned suppression in Groups $\mathrm{C}$ and C.CS.REM $(U=$ $63.50, p=.62$ ), and equivalent conditioned suppression in Groups $\mathrm{U}$ and U.CS.REM $(U=64.00, p=.90)$. Thus, the observed pattern of results in Experiment 2 was not a function of our response measure (i.e., time vs. log time) or our use of a parametric statistical test.

(Manuscript received February 27, 1995; revision accepted for publication June 30,1995 .) 